\title{
A DISCUSSÃO ÉTNICO-RACIAL NEGRA, CONSTRUINDO SABERES NOS PROCESSOS FORMATIVOS DE PROFESSORES
}

Josiane Beloni de Paula ${ }^{1}$

Elison Antonio Paim²

Este trabalho visa debater um tema presente na escola e consequentemente na sociedade, que é a erradicação do racismo, baseado em autores, como Kabengele Munanga, Eliane Cavalleiro e Petronilha Silva entre outros, os quais fomentam a discussão da educação antirracista. Os autoresavaliam que a maneira mais de implementarmos mudanças é investirmos primeiramente nos processos formativos de professores, seja inicial ou continuado, para então a temática e as ações chegarem às crianças e suas famílias, transformando o imaginário social. Por meio, deste repensar, os professores irão contagiando seus pares e colocando na pauta da escola e da vida uma temática tão emergente e importante no mundo atual, o qual estamos construindo, quebrando barreiras e lutando para valerem os direitos, já há tempos adquiridos, porém ainda não exercidos.

Dessa forma, o objetivoaqui é problematizar um tema já muito estudado, porém com um diferencial, não vem mais com o único intuito de pontuar o problema, ou seja, de que existe o racismo, o preconceito e a discriminação no Brasil, mas investir na transformação de um cenário construído ao longo da história e camuflado numa tentativa de invisibilidade de sua existência, através da implantação do mito da democracia racial(DA MATTA, 1981), ou seja, na sociedade brasileira não há discriminação, as três "raças" formadoras, branca (colonizador), negro (escravizados), índios-vermelhos (domesticados/dizimados), convivem em plena harmonia de

\footnotetext{
${ }^{1}$ Josiane Beloni de Paula, Doutoranda em Educação pela Universidade Federal de Santa Catarina UFSC. Sob orientação do professor Dr. Elison Antonio Paim. Mestra em Educação pela Universidade Federal de Pelotas - UFPel (2014). Integrante do Grupo de Pesquisas Patrimônio, Memória e Educação (PAMEDUC -UFSC) e do Grupo de Pesquisas Rastros Universidade são Francisco - SP (USF). e-mail: belonijbc@hotmail.com

${ }^{2}$ Prof. Dr. Elison Antonio Paim, Professor permanente do Programa de Pós-Graduação em Educação (PPGE), Vice coordenador do Mestrado Profissional em Ensino de História (Profhistória/UFSC) e de Estágio Supervisionado em História (UFSC). Vice-líder do grupo de Pesquisas Patrimônio, Memória e Educação (PAMEDUC-UFSC), vice-líder do Grupo de Pesquisas Rastros (USF), membro do Grupo de Pesquisas Kairós (Unicamp). e-mail: elison0406@gmail.com.
} 
identificação brasileira, com uma cultura hegemônica, negando assim sua presença e diferença na constituição atual da sociedade.

Sendo assim, a intenção é gerar referências, outros pensares, è um estudo, uma visão comprometida com a temática em questão, mas que pode servir para incentivar tantos outros preocupados e ainda sem iniciativas, a iniciarem mudando suas posturas para trazerem suas reflexões para escola como Freire nos estimula, "Essas iniciativas, nascidas na escola, nos movimentos sociais, levam a sociedade a perceber a possibilidade de mudança de atitudes e de uma outra visão de mundo - justo, igualitário e possível - construída por todos e para todos",(FREIRE, 2000). Com estas práticas de resistência ${ }^{3}$, as quais dão visibilidade à situação histórica e atual do negro na sociedade brasileira.

O que se almeja é a erradicação, como de uma doença (CRUZ, 2014) e aqui, o racismo visto como uma doença social e em contrapartida, investir no contágio, ao contrário da doença contagiar com a cura, sendo práticas de resistências realizadas por educadores um remédio, uma cura paliativa, mas que contagiando outros e outros se tornará um antídoto para redução dos danos e erradicação do racismo.

Construindo processos formativos de professores, que instigue e impulsione a repensar as práticas na escola e sociedade, gerando novos modelos, ou seja, situações de revisão dos conceitos impregnados historicamente.

As ações afirmativas são políticas públicas de reparação de dano causando, as práticas de resistências, são ações afirmativas não institucionalizadas, são pequenas ações, que são capazes de levar a grandes transformações, como para Freire das situações limites, criam-se inéditos viáveis e destes outros e assim sucessivamente.

Trabalhos realizados sobre a etnia negra na sociedade brasileira, mais especificamente na sala de aula, iniciativas que devem ser estudadas e divulgadas, para que dessa forma haja maior visibilidade do problema e, além disso, possíveis

\footnotetext{
${ }^{3}$ Resistência conceituada por Paulo Freire como o oposto de desistência. Resistência pressupõe briga entre desiguais, onde "a boniteza de ser gente se acha, entre outras coisas, nessa possibilidade e nesse dever de brigar" (FREIRE, 2000, p.67). A resistência freireana relaciona-se com possibilidade de mudar 0 mundo, de não se acomodar, não fraquejar, intervir. A resistência é prática de rever conceitos da visão dominante.
} 
soluções, não definitivas, mas realizáveis e as quais instigam a reflexão do panorama social, além de despertar uma possível disponibilidade ao trabalho em prol da etnia negra. Qualificando assim os processos formativos de professores, os quais tendo acesso a tais práticas poderão iniciar sua caminhada.

Nesse panorama, o educador quando preza e luta pela educação libertadora tem um papel central, auxiliar a desvelar as situações-limites para que o sujeito construa o pensamento crítico, pois encharcado de suas vivências de opressão este não vislumbra seu viver, seus direitos ou a falta deles. Com o pensamento crítico o sujeito rompe com a situação de opressão, vai havendo a conscientização, a tomada de consciência diante de sua realidade e do seu direito de ser mais, também do seu dever de lutar para que de fato isso ocorra, sendo assim tornar-se sujeito e poderá gerar situações libertadoras e nos traz como o anúncio que é o "inédito viável", a resistência, a transformação da situação. Como para Freire,

O inédito - viável não é, pois, uma simples junção de letras ou uma expressão idiomática sem sentido. É uma palavra na acepção freireana mais rigorosa. Uma palavra-ação, portanto, práxis, pois não há palavra verdadeira que não seja práxis, daí, quer dizer que a palavra verdadeira seja transformadora do mundo (1975, p.91). Uma palavra epistemologicamente empregada por Freire para expressar, como enorme carga afetiva, cognitiva, política, epistemológica, ética e ontológica, os projetos e os atos das possibilidades humanas (STRECK, 2010, p.224).

Nas práticas de resistência em sala de aula, são soluções praticáveis muitas vezes despercebidas, que Freire nos traz como um caminho para transformação e sendo o inédito viável concretizado, este abre portas para diversos outros, acontecendo assim à reconstrução da nova sociedade almejada por todos que se engajam na luta para alcançá-la.

Este estudocomeçou a pegar forma, na década de 2000, com a caminhada deeducadora e pesquisadora, a qual sempre foi permeada de duas inquietações, a educação vista como um processo de construção do ser, em sua forma integral, de ser e estar no mundo e a problemática do grupo de pertencimento dos indivíduos envolvidos neste processo, principalmente do grupo étnico negro. Sendo assim, no início a análise foi empírica, uma mistura de angustias, indignações e sentimentos de 
possibilidades de ações para transformação, passando a problema de pesquisa, com a denominação de práticas de resistência negra na sala de aula.

A referida pesquisapermeou observações em escolas e trabalhos realizados pelas mesmas. Buscamosvisualizarações inovadoras e transformadoras, construídas dentro da escola, por professores e alunos preocupados com os rumos da consciência humana,para os sujeitos deixarem de ser expectadores da própria vida, se apoderando de seus direitos, para tornarem-se atores e autores de suas histórias como voz ecoante e não mais como segunda voz, pouco ou nada ouvida. Além disso, foram realizadasentrevistas com professores, referentes a seus saberes e constituições como sujeitos e profissionais.

Após diversas leituras e aprendizados levaram a construção detrabalhos como: artigo de especialização ${ }^{4}$ e dissertação de mestrado ${ }^{5}$, os quais instigam novos saberes e lutas. No presente momento, estáem construção a tese de doutorado, a qual permanecerá agregando conhecimentos referentes à temática étnico-racial negra.

Analisando, por meio de um levantamento o crescimento da apresentação de trabalhos, realizados por professores em suas salas de aula, referentes à temática da etnia negra, no evento de formação continuada de professores intitulado "Encontro sobre o PODER ESCOLAR" ${ }^{\prime \prime}$, do ano de 2001 a 2010.

Uma pesquisa a qual será realizada com as professoras e professores, preocupados com a situação do negro na escola e sociedade brasileira, levantando o debate e construindo práticas diferenciadas no interior da escola, para reconstruir as identidades deformadas pelo racismo e contar uma história com suas vozes e não mais somente ouvir a palavra do colonizador.

\footnotetext{
${ }^{4}$ Artigo de conclusão da Especialização: Erê vozes das infâncias: A construção das identidades étnicoraciais negras na escola. UFPel, 2007.

${ }^{5}$ Dissertação de Mestrado: Colorindo invisibilidades: um estudo de caso acerca de práticas de resistência negra na escola, UFPel, 2014.

${ }^{6}$ Criado em 2001, o projeto de formação "Encontros sobre o Poder Escolar" tem como objetivo investir no desenvolvimento da autonomia e capacidade da comunidade escolar, contribuindo para a qualificação da oferta da educação básica através da divulgação e discussão de experiências, diálogos e o contato com pesquisadores da área. Realizado na cidade de Pelotas-RS.
} 
Dessa forma, percebemos que este trabalho não se esgota e sim se revigora a cada debate e nos instiga a continuar, partimosdo diálogo com o pensamento de Munanga quando questiona,

Como, então, reverter esse quadro preconceituoso que prejudica a formação do verdadeiro cidadão e a educação de todos os alunos, em especial os membros dos grupos étnicos, vítimas do preconceito e da discriminação racial? Não existem leis no mundo que sejam capazes de erradicar as atitudes preconceituosas existentes nas cabeças das pessoas, atitudes essas provenientes dos sistemas culturais de todas as sociedades humanas. No entanto, cremos que a educação é capaz de oferecer tanto aos jovens como aos adultos a possibilidade de questionar e desconstruir os mitos de superioridade e inferioridade entre os grupos humanos que foram introjetados neles pela cultura racista na qual foram socializados. Apesar da complexidade da luta contra o racismo, que consequentemente exige várias frentes de batalha, não temos dúvida de que a transformação de nossas cabeças de professores é uma tarefa preliminar importantíssima. Essa transformação fará de nós os verdadeiros educadores, capazes de contribuir no processo de construção da democracia brasileira, que não poderá ser plenamente cumprida enquanto perdurar a destruição das individualidades históricas e culturais das populações que formaram a matriz plural do povo e da sociedade brasileira. (MUNANGA, 2005, p.17)

Com Munanga, podemos verificar a importância de uma mudança individual para uma transformação educacional e, consequentemente, social; o professor é o propulsor do ideal de uma sociedade justa, propondo reflexões e ações que revoguem, desconstruam e reconstruam as normas apregoadas pelo sistema vigente.

Outro pensamento de Freire com o qual compartilhamos é a não existência de uma neutralidade, mas sempre de uma posição: ou estamos do lado do opressor ou do oprimido, e dessa forma, toda ação é política. Então, é uma posição que devemos tomar em relação à discriminação e sua erradicação, é uma atitude que precisamos exercitar; se lutamos por uma sociedade justa, se nossa opção é libertadora, devemos trabalhar pela equidade, pela convivência com o diferente e não por sua negação.

Para que haja uma transformação, uma descolonização das mentes é necessária à realização de uma práxis, de começarmos por nós, cada um deixando para suas gerações experiências de amorosidade, de respeito a todos os seres da natureza. É, sem dúvida, uma construção coletiva. Dá-sepeladesnaturalização, dos preconceitos, dos desrespeitos, partindo para uma construção de sujeitos que buscam 
a sua conscientização, descobrindo seu inacabamento e procurando "ser mais". Ou seja, exercitando uma capacidade estritamente humana, a qual nos diferencia do restante dos seres da natureza: a reflexão.

Dessa forma, podemos visualizar práticas inovadoras, entendidas como ações capazes de proporcionar uma possível transformação efetiva de ações individuais e coletivas, as quais intervenham nas estruturas sociais pré-estabelecidas, rompendo com a lógica discriminatória. Devemos iniciar a reflexão também em salas de aulas, uma contribuição para construção de uma sociedade realmente para todos e não, ingenuamente como temos hoje, baseada no mito da democracia racial.

Assim, legalmente todos têm os mesmos direitos, mas no momento de exercitá-los, encontramos obstáculos intransponíveis tais como: agrandemídia, que sempre apresenta o negro como personagens menosprezados; os livros didáticos, os quaisainda trazem massivamente à imagem de pessoasbrancas, com modelos europeus; a religião, seguindo a qual o país adere aos feriados, católicos; a escola, que não discute diferentes culturas...

Não podemos deixar de refletir sobre estas problemáticas, pois:

Trata-se, de fato, de uma questão complexa, sobretudo se considerarmos que em qualquer currículo há compromisso com respeito ao tipo de pessoas que queremos formar, como elas agirão com os outros seres humanos, como formarão suas identidades, como assumirão responsabilidades sociais etc. (BRACHT; ALMEIDA, 2006)

Nossa pretensão é que os processos educativos de professores sejam permeados de questionamentos, referentes aos mais diversos assuntos, ressaltando a importância de reflexão acerca do papel da escola, das ações dos sujeitos na sociedade, inclusive dos professores em momentos difíceis que vivemos de desvalorização e inversão de valores, do ter ao invés do ser, no qual o compromisso com a interculturalidade ${ }^{7}$, com as múltiplas formas de estar no mundo.

\footnotetext{
${ }^{7}$ A interculturalidade é então concebida como uma estratégia ética, política e epistêmica. Nesta perspectiva, os processos educativos são fundamentais. Por meio deles questiona-se a colonialidade presente na sociedade e na educação, desvela-se o racismo e a racialização das relações, promove-se o reconhecimento de diversos saberes e o diálogo entre diferentes conhecimentos, combate-se as diferentes formas de desumanização, estimula-se a construção de identidades culturais e 0 empoderamento de pessoas e grupos excluídos, favorecendo processos coletivos na perspectiva de
} 
São vários os estudiosos trabalhando para a construção de uma nova educação, de um novo projeto escolar que seja para todos. São grupos de trabalho que tratam da temática do negro nas mais diversas situações: as questões das cotas, materiais didáticos, mídia, relações sociais, institucionais, étnico-raciais, educação antirracista - e o que mais envolver esses sujeitos - a fim de denunciar a opressão e resistir por meio de ações e práticas que possibilitem a efetiva transformação deste panorama.

Nesta perspectiva, vale ainda ressaltar alguns autores, para esta construção, bem como seus trabalhos, que resultam num apanhado consistente que consolida as Teorias da Educação Antirracista, que estabelece como fundamento a igualdade entre os humanos.

Para tanto, trazemos de Eliane Cavalleiro, a referência do que apregoa a educação antirracista:

No cotidiano escolar, a educação anti-racista visa à erradicação do preconceito, das discriminações e de tratamentos diferenciados. Nela, estereótipos e idéias preconcebidas, estejam onde estiverem (meios de comunicação, material didático e de apoio, corpo discente, docente etc.), precisam ser duramente criticados e banidos. É um caminho que conduz à valorização da igualdade nas relações. E, para isso, o olhar crítico é a ferramenta mestra.

Almeja, nesse sentido, possibilitar aos indivíduos pertencentes ao grupo de atingidos pelos preconceitos a reconquista de uma identidade positiva, dotada de amor e orgulho próprios. Nela é permanente o combate aos sentimentos de inferioridade e superioridade, visto que a palavra máxima da educação antiracista é a igualdade entre os humanos (CAVALLEIRO, 2001, p.150).

Podemos perceber que se constrói um novo olhar acerca da educação, um enfoque no todo, na escola formada por todos seus atores, na qualo preconceito e a discriminação podem ser visualizados e exterminados, via problematização e construção de um pensamento crítico.

Sendo assim, esta pesquisa trata de uma problematização sobre a temática étnico-racial negra na escola, a qual vem sendo colocada em pauta pela sociedade, emborasuperficialmente, porém se configura como algo suscetível de mudança, tanto

projetos de vida pessoal e de sociedades "outras". A referência às contribuições de Paulo Freire e de Frantz Fanon é constitutiva da construção de propostas educativas que assumam a perspectiva da educação intercultural crítica e decolonial.(CANDAU; RUSSO, 2010) 
pelo caráter mutante da sociedade, como da dinâmica do conhecimento cientifico e da produção de novos conhecimentos; É um estudo que inicia-se aqui, tendo como objetivo estimular a ampliação e divulgação de iniciativas de erradicação do racismo, através de processos formativos de professores.

Verificando que estas práticas potencializam os processos de aprendizagens; estes pontuam e geram a reflexão sobre o preconceito e a discriminação presentes em nossas realidades, desafiando-nos para pensar sobre eles, tendo em vista a importância dessas inovações no cenário social e os impactos educacionais decorrentes.

\section{REFERÊNCIAS}

BRACHT, V; ALMEIDA, F. Q. Emancipação e diferença na educação:uma leitura com Baumann.Campinas, SP: Autores Associados, 2006.

CANDAU. V. M. F; Russo, K. Interculturalidade e Educação Na América Latina: uma construção plural, original e complexa. Rev. Diálogo Educ., Curitiba, v. 10, n. 29, p. 151-169, jan./abr. 2010

CAVALLEIRO, E. (Org.), Racismo e Anti-Racismo na Educação: repensando nossa escola.São Paulo: Summus, 2001.

CRUZ, J. B. Colorindo invisibilidades: um estudo de caso acerca de práticas de resistência negra na escola. 2014. 78f. Dissertação (Mestrado em Educação) Programa de Pós-Graduação em Educação, Faculdade de Educação, Universidade Federal de Pelotas, Pelotas, 2014

DA MATTA, R. Relativizando: uma introdução à Antropologia Social Petrópolis: Vozes, 1981.

FREIRE, P. Pedagogia da Autonomia: Saberes necessários à prática educativa. 15 ed. Rio de Janeiro: Paz e Terra, 2000.

MUNANGA, K. Superando o racismo na escola. 2 ed. MEC/Secad, 2005.

SILVA, P. B. G; SILVÉRIO, V. R. Educação e Ações Afirmativas: entre a injustiça simbólica e injustiça econômica. Brasília: Inep, 2003. 
STRECK, D. R; REDIN, E. ZITKOSKI, J. J. Orgs. Dicionário Paulo Freire. Verbete: Inédito Viável (Ana Maria Freire).2ª Ed. Belo Horizonte: Autêntica, 2010. 